\title{
Climate Change and Livelihoods-Based
}

\section{Adaptation: Experiences and Lessons from Bringing the Two Discourses Together}

\author{
Atiq Kainan Ahmed ${ }^{1}$, Abu Wali Raghib Hassan ${ }^{2}$, Afsana Yasmeen ${ }^{3}$ \\ ${ }^{1}$ Asian Disaster Preparedness Center (ADPC), Thailand. \\ ${ }^{2}$ Department of Agricultural Extension (DAE), Bangladesh. \\ ${ }^{3}$ Integrated Coastal Zone Management Programme (ICZMP), Bangladesh.
}

\begin{abstract}
In past two decades or so, the 'livelihoods' centric approaches in rural development have grown globally in a rapid manner. These are elaborated in diverse forms and framed in diverse social-ecological systems. In Bangladesh, these approaches have started to get integrated into development sectors but are also entwining with climate change adaptation and disaster risk reduction where the efforts are largely grown through various demonstrative projects and interventions. These applications are now yielding interesting lessons and insights that are worth bringing into contemporary discourses and framings of policy and practices. This paper looks into some of such evidence-based lessons, particularly reflecting the agriculture sector initiatives on the ground. Findings indicate that the integration of livelihoods approaches should not just be 'optional' features, rather these are 'essence' for future success. The paper also points out that as the new post-2015 global policy framings are now moving ahead with formulating newer implementation arrangements, the new set of strategic and operational roadmaps in Bangladesh should build on these lessons. Livelihoods-based approach inherently has a great potential to integrate climate adaptation, risk management, and pro-poor resilient development in a practical way.
\end{abstract}

Keywords-Climate Change, Adaptation, Livelihoods, Resilience, Sustainable Development Goals, Socialecological System.

\section{INTRODUCTION}

The discourse of 'livelihood' is understood as 'capabilities, assets (e.g. stores, resources, claims or access) and activities required for a means of living [1,2]. A livelihood is sustainable when it can cope with and recover from stresses or shocks and maintain or enhance its capabilities and assets both now and in the future, while not undermining the natural resource base $[1,4]$. In social and economic development practices, the concept of livelihood evolved from diverse origins and in recent decades have formed into a more coherent set of ideas during through a wide body of practical, professional and academic endeavors [2-4]. In early part of the current century, mainstream development paradigm has started to shift from an economic 'growth-centric' focus to a more 'sustainable development' focused approaches where the livelihoods-centric approaches have been identified as new paradigm and also as a significant tool to move ahead [5]. The livelihoods-centric approaches have also started integrating with the wider efforts of pro-poor risk management, vulnerability reduction, strengthening resilience and a myriad efforts to make development and climate-smart $[5,2,3,6,7]$. The evolution of various conceptual developments associated to climate change, vulnerability, resilience and disaster risk management have also influenced the paradigm shift in a bigger way [6-10]. The development of a sustainable livelihoods framework (SLF) accelerated the extension of livelihoods research into the wider policy and practices and widely used by international development partners, donors, nongovernment organizations and remained useful application in diverse contexts and situations [2,11,12]. Livelihoods perspective places people at the center of the analysis, located within, rather than dominated by, ecosystems, technologies, political contexts, markets and resource networks $[3,13]$.

In the context of contemporary Bangladesh, the issue of climate change and livelihoods issues are one of the most critical challenge and also a key research agenda that requires to move ahead with more and more evidencebased research and analysis. Bangladesh as a country has now moved up into a middle income country (MIC) status where new livelihood opportunities are emerging often in the non-farm sectors as well. The numbers of small shops, tailoring and other craft enterprises, rickshaw pullers, petty traders in villages and local bazaar centers have grown substantially. For many of the poor, who have little or no access to land, their primary asset remains their labor - a healthy pair of hands is critical to their 
livelihoods [14,15]. However, whether people are engaged in agricultural laboring or in the non-farm sector they continue to be marginalized due to climate change. Climate change is putting the livelihoods systems into an unprecedented level of risks all around the world [16].

Bangladesh is one of the most climate vulnerable countries in the world with multiple climate vulnerable hotspots [42,34,35] (See figure 1). In Bangladesh, livelihoods are increasingly exposed to the any major trends, shocks and seasonality relating to both climatic and non-climatic or societal changes of exogenous and endogenous in nature $[17,18]$. Becoming vulnerable to changing climate more frequently is equated with to the livelihoods losses and damages and making the system further unstable to any future risks. Climate change impacts can also increase stresses and shocks to the sustainable livelihoods and would anticipate to bring more human suffering and deprivation $[10,16]$.

Bangladesh has a relatively long history of implementing some long-run livelihoods-centric programs in various eco-systems of the country. Major programs that adopted and promoted livelihoods-based approaches in their central strategies are: Chars livelihoods Program (CLP) supported by DFID and Bangladesh government [22], Integrated Coastal Zone Management Program (ICZMP) with DFID and Dutch financial support [29-32], Rural Livelihood Program (RLP) implemented by CAREBangladesh [23], Livelihoods adaptation to climate change (LACC) initiative implemented by the Department of Agricultural Extension (DAE) under the Ministry of Agriculture (MoA) in Bangladesh [24-26] are among others.

This paper looks into experiences from Bangladesh and brings a critical analysis of few factors that remained essential in making a seamless integration of livelihoodsapproach in climate change adaptation and disaster risk reductions in the country. Gradually, the paper through a narrative discussion will also clarify the entwining link of livelihoods-based approach climate change adaptation actions and will also make synergic conclusions for the newly evolving global policy frameworks of Sustainable Development Goals (SDGs) [19], Paris Agreement on Climate Change [20] and Sendai Framework for Disaster
Risk Reduction (SFDRR) [21]. The proceeding discussion will also attempt to point out how the livelihoods-based approaches to adaptation can play pivotal role in harmonizing these ambitious global policies and practically in devising modalities for linking the national level efforts to the local level and for managing pro-poor risk sensitive development in Bangladesh.

\section{MATERIALS AND METHODS}

The paper adopts a critical review and analysis of materials, information and primary data from three layers. These layers are:

a) the existing project situation assessments where the livelihoods framework was adopted as major approach to identify the gaps and key approach incorporated in the agriculture sector particularly focusing the project pilot areas under the 'Support to Strengthening Disaster Preparedness in Agriculture Sector in Bangladesh (SSDP)', 'Livelihoods adaptation to climate change (LACC)' and 'Disaster and Climate Risk Management in Agriculture (DCRMA)' projects;

b) climate change adaptation options that were developed from research and experiences respective to targeted dryland and coastal, and flood prone areas of the country and gradually a livelihoods-based climate change adaptation strategy was proposed; and finally

c) Empirical data that the authors have collected from some stakeholder consultations, interviews and expert discussions carried in a recent round of field visit to the Northern drylands as well as in the Southwestern coastal zone of Bangladesh.

The materials and insights of the Integrated Coastal Zone Management Program (ICZMP) [30-32] were also looked at in a limited manner for analyzing the adoption of the livelihoods issue in the coastal zone. These set of works in the coastal zone seemingly also contributed in developing the national coastal policy [29], coastal development strategy (CDS) earlier [30,31] and more recently the delta development initiative in Bangladesh [42]. 


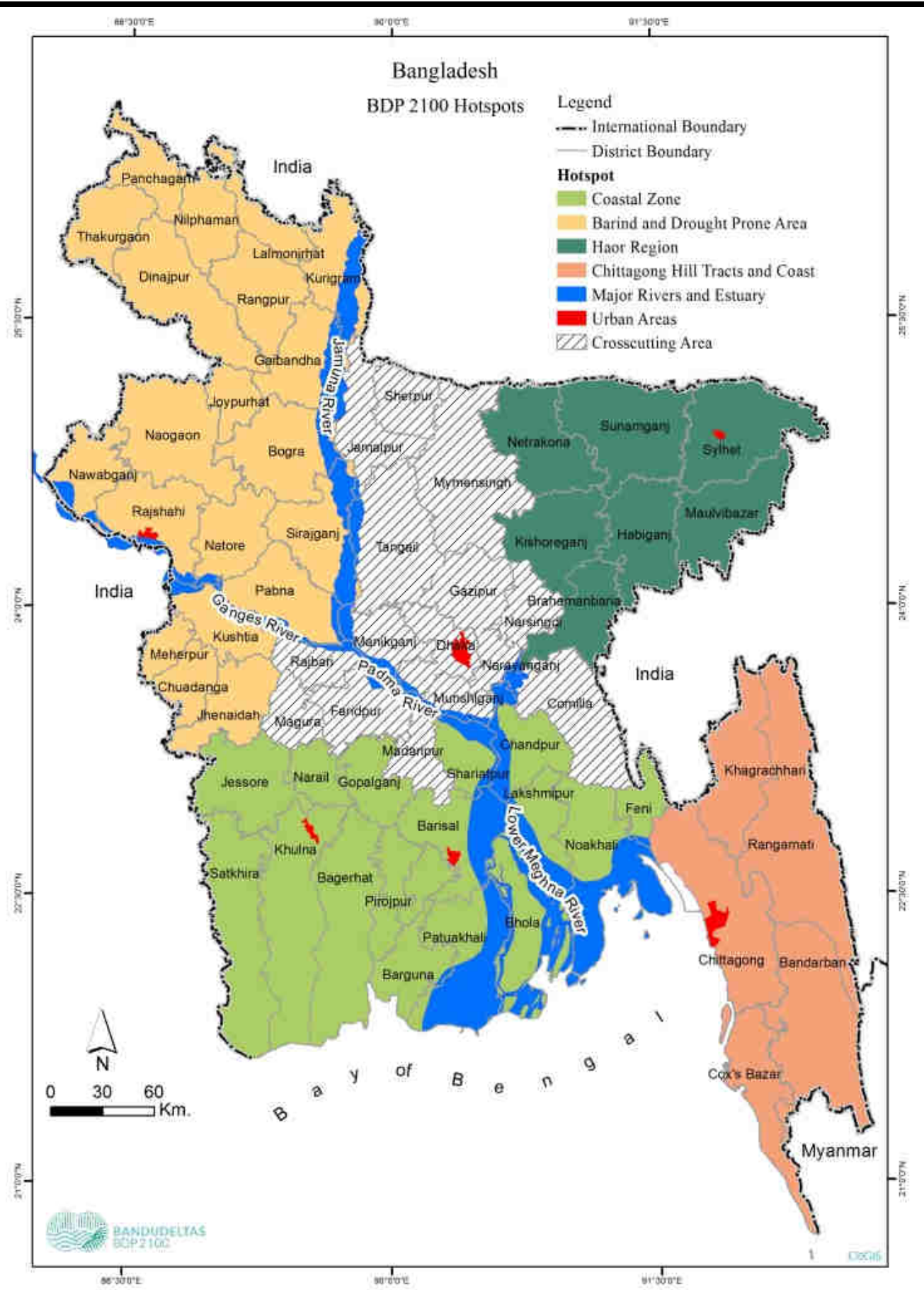

Fig.1: Climate vulnerable hotspots in Bangladesh (Source: BDP2100, CEGIS).

\section{FINDINGS}

The findings are shared in this paper are primarily from the agriculture sector initiative where the livelihoodsbased adaptation approach was adopted to mainstream climate change adaptation and disaster risk reduction in a systematic way. In elaborating the findings and results various issues including: people's perceptions, problems and risks; frameworks tested; and the measures that were undertaken for adaptation and risk management are sequentially narrated below.

\subsection{Perceptions, problems and risks}

In the northwestern dryland areas of Bangladesh it was observed that the livelihoods are severely affected by drought situation. The predominant livelihoods groups such as the small farmers, fishers, wage labourers and petty businessmen remains on top of the impacts of changing climate and variable seasons (See figure 2). Local people in these conditions have also perceived that their boro, aus and winter vegetable production, fruits (several varieties of mangoes) remained affected due to temporal variations in rainfall, temperature and variability 
in drought occurrences. The access to boro, aus and rabi remains largely dependent over the access and availability of the irrigation water. Failure in getting access to Deep Tube Well (DTW) water in the non-irrigated areas and the occurrence of several anthropogenic factors (e.g. electricity failure, high price of agricultural input) remains as the major form of vulnerability for the farmers. The wage laborers face unemployment and crises of failed migration. Petty traders find difficulties in getting buyers on a regular basis. In this thriving situation, the large businessmen and large (or rich) farmers were found vulnerable by a lesser degree. However, these groups are found vulnerable to the climatic hazards in a covariant (all in analogous condition) way but having access to the higher degree of assets other than the natural (mostly financial, social and physical) the group actually keep them out of severe vulnerabilities caused by climatic conditions.

Local people hold various social and individual perceptions towards the current and past risks existed in the area. People perceive that the current climate in the area has been behaving differently from the past few decades. The seasonal cycle (locally called rituchakra) has changed, droughts became more frequent, pest and disease incidences increased, average temperature has increased in the summer while winter has shortened and the severity of some winter days increase. However, people found difficulties in expressing the degree of changes.

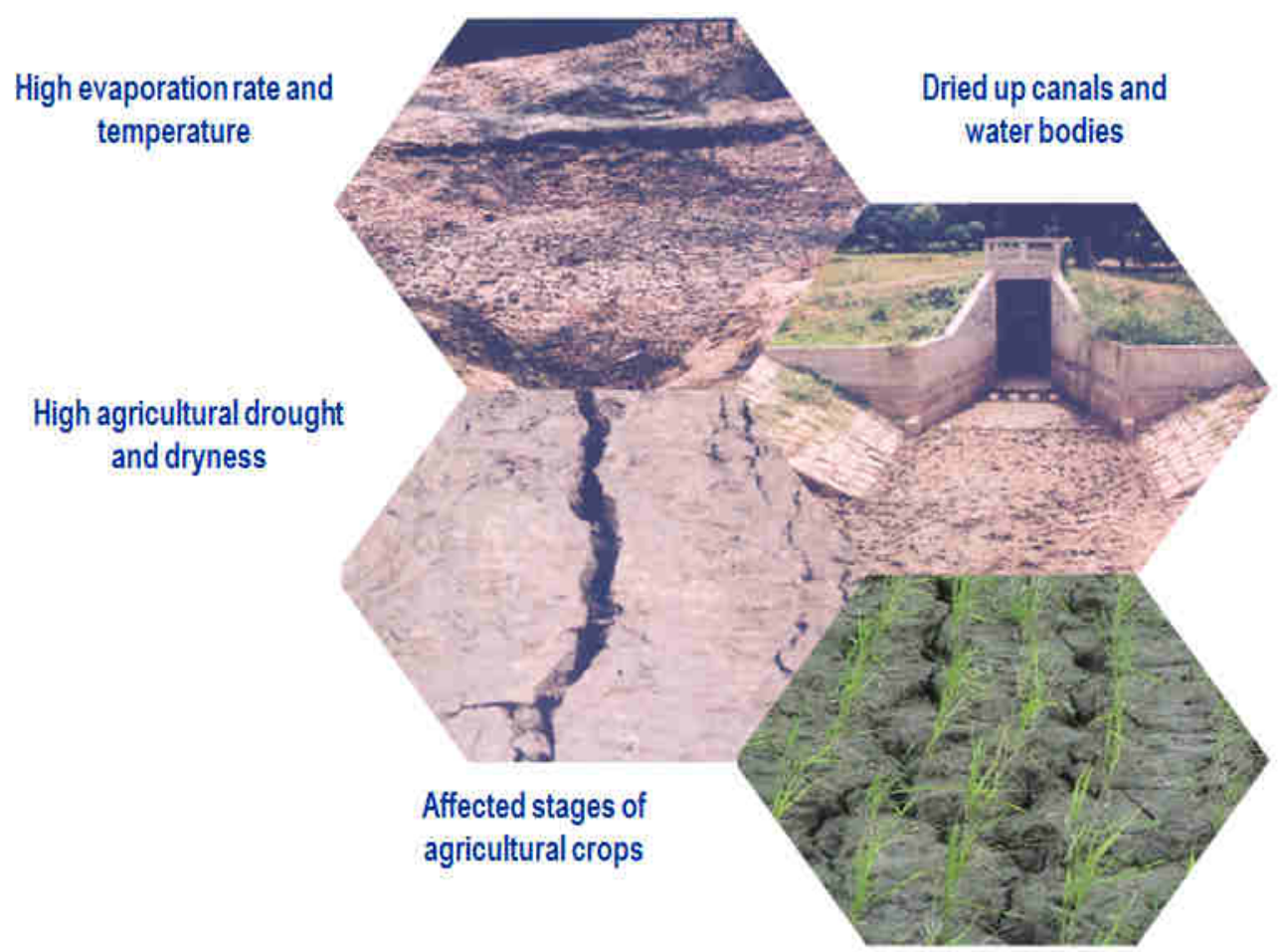

Fig.2: The drier northwestern districts of Bangladesh face various types of drought effects that impacts the various types of activities in the region where the major livelihoods groups such as the small farmers, fishers, wage labourers and petty businessmen remains on top of the impacts of changing climate and variable seasons (Source: Ahmed \& Chowdhury 2006).

In the dry climatic conditions (in the northwestern districts), some local/traditional adaptive practices are existing in the study area. Four major types of adaptive practices: a) traditional responses (e.g. pond and dighi excavation, retention of rainwater in khari and canals, shedding, tillage, breaking top soil), b) state supported responses (e.g. DTW facilitated irrigation), c) alternative responses (e.g. adoption of mango farming, orchard developing), and d) some domestic responses (e.g. alternative livestock and poultry/birds rearing) are existing in the study area. The project found that the successes derive from these adaptive practices are of relative nature: some are promising, some brings a limited success and some have only a low efficacy in severe conditions of severe drought or in variable climatic conditions.

\subsection{Framework formulated and adopted}

The livelihoods-based climate change adaptation approaches in agriculture sector was developed through the gradual development and adoption of livelihoods targeted interventions under three sequentially developed 
donor supported and government collaborated projects in the agriculture sector in Bangladesh. The three projects respectively are: a) Support to Strengthening Disaster Preparedness in Agriculture Sector in Bangladesh (SSDP) (2004-2005); b) Livelihoods adaptation to climate change (LACC) project in two phases (2005-2007, and 2008-2009); and c) Disaster and Climate Risk Management in Agriculture (DCRMA) project (20102014). These set of pioneering projects in agriculture sector was implemented in several districts in the parts of northwestern dryland, riverine central areas (the Brahmaputra/the Jamuna rivers) and the southern coastal part of Bangladesh. These projects were hosted by the Department of Agricultural Extension (DAE) and the Comprehensive Disaster Management Program (CDMP) of Bangladesh with the technical collaborations from various technical organizations including Food and Agriculture Organization (FAO), Asian Disaster Preparedness Center and Center for Environmental and Geographic Information Services etc. [24-26]. The livelihoods-based climate change adaptation initiative builds on the existing efforts of agricultural disaster risk management in agriculture sector in Bangladesh such as the SSDP project [33]. A targeted adoption was more considered during the LACC and DCRMA projects in phases.

In agriculture sector, the LACC project among these was the first project which has considered the livelihoods approach as a strategic modality for climate change adaptation. The LACC project promoted climate change adaptation and disaster risk reduction processes and capacities for sustainable livelihoods and food security in the rural sectors including crops, livestock, fisheries and forestry and other key factors of rural livelihoods in the drought prone and coastal regions of Bangladesh. The project aimed for: a) introduce, improve and further strengthen institutional and technical capacities for improved adaptation to climate variability and change; addressing technology needs for adaptation, awareness raising and climate information needs; b) implement in a participatory way and jointly with local communities good practices and strategies to effectively address climate change adaptation and disaster preparedness and develop strategies for their long term sustainability; and c) provide recommendations for up-scaling and mainstreaming of successfully pilot tested livelihood adaptation options into development planning and policy decision making. The project was implemented in two phases [27,28].

Agriculture sector initiatives adopted a framework focusing on livelihoods-based approach where the approach starts in a bottom up manner comprising of four key sets of activities: a) assessing current vulnerability; b) assessing future climate risks; c) testing of adaptation options; and then d) designing adaptation strategy for the livelihoods groups through an active stakeholder engagement and feedback process. Livelihood groups such as small farmers, fishers, wage laborers, petty businessmen and others were considered as the key targets under the project. The framework adopted initially and then gradually customized by the agriculture sector in Bangladesh is shown in the figure 3.

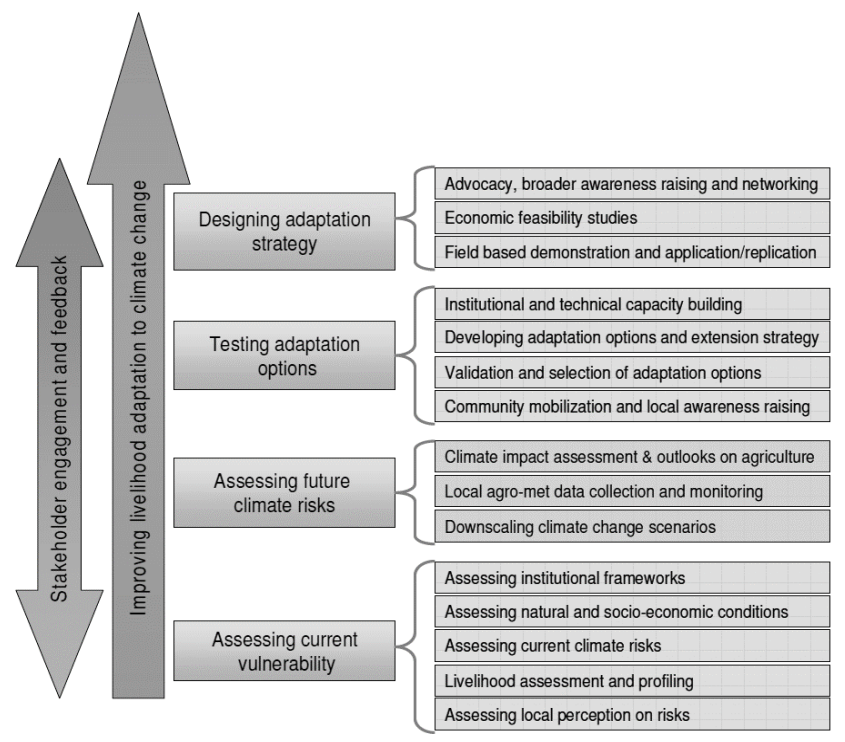

Fig.3: Framework adopted by the LACC initiative that focus on livelihoods-based approach (Source: Selvaraju, R et al. 2006).

\subsection{Adaptation and risk management measures}

The livelihoods adaptation approach was found as a critically needed approach for the agriculture sector in Bangladesh as the sector was found highly vulnerable to the changing 'climatic conditions' as well as the 'anthropogenic factors' that are contributing towards the vulnerability of the life and livelihoods of the people $[17,24]$. Climatic factors are creating the vulnerabilities but due to the anthropogenic capabilities (and the access to various forms of assets) livelihoods are becoming more vulnerable and leading towards disasters and losses. This is a dual effect of climatic and anthropogenic conditions at the same time.

The agriculture sector projects for the dryland areas such as the SSDP and LACC-I project recommended that multiple pathways to improve adaptive responses that would comprise of both long-term and short-term adaptive measures should be adopted by the livelihood groups. Such multiple pathways could comprise of: a) the treatment of the climatic risks through physical adaptive measures if possible (e.g. planned physical water resources management); b) the adaptation to climate change through improved non-structural disaster risk 
prevention and preparedness activities; c) the adjustment/alteration of agricultural practices (e.g. setting up adequate cropping pattern and selection of tolerant crops); and d) the creation of alternative livelihoods opportunities for future other than traditional crops. Selvaraju, R et al. [25] pointed out that successful local adaptation to climate variability and change requires multiple pathways with well planned, interrelated shortand long-term measures, including:

- Adopting physical adaptive measures: such as excavation, re-excavation of canals, mini ponds, irrigation, storage facilities for retaining rain water;

- Adjusting existing agricultural practices: such as adjustment of cropping patterns, selection of droughttolerant crop varieties;

- Better storage of seeds and fodder; dry seedbeds; or adopting alternative, cash crops such as mango and jujube (Ziziphus jujuba);

- Adjusting socio-economic activities: such as livelihood diversification, market facilitation, small-

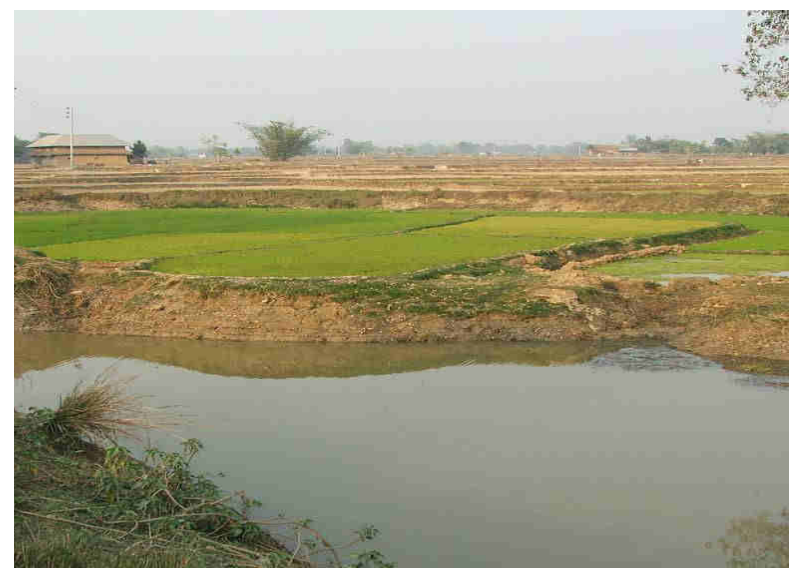

scale cottage industries, integration of traditional knowledge;

- Strengthening local institutions: such as self-help programs, capacity building and awareness raising for local institutions;

- Strengthening formal institutional structures: such as local disaster management committees and financial institutions;

- Formulating policy to catalyze enhancement of adaptive livelihood opportunities;

- Creating awareness and advocacy on climate change and adaptation issues;

- Supporting better research: such as on-farm links to new or improved crops including drought-tolerant varieties, and other conducive and adaptive technologies.

Figure 4(a) and 4(b) are depicting some adaptation measures respectively for dry zones.

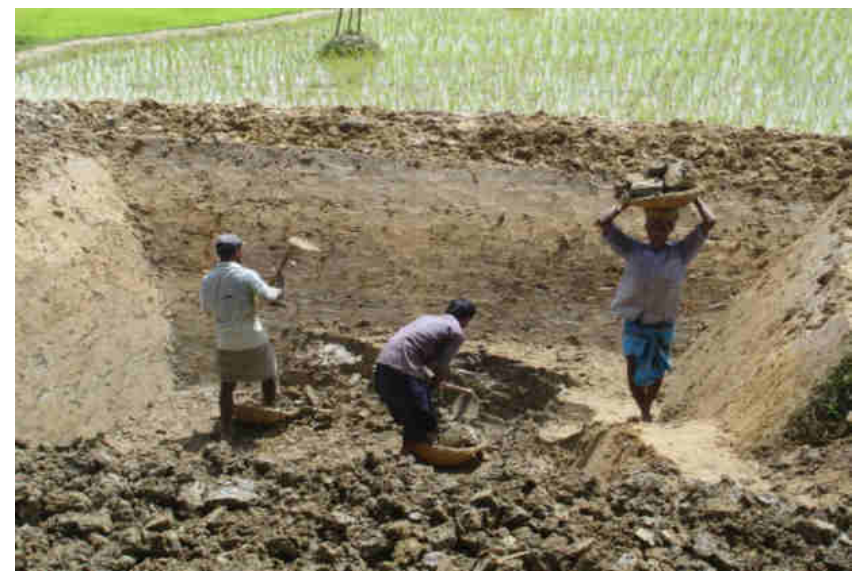

Fig.4: Dryland example: (4a - left) An innovative small-farmer used his agricultural land and pond optimally and managed to get a crop while others in the area did not manage to cultivate in the same season. (4b-right)'Dig ponds deeper, not wider'. A local innovative adaptation measure retainin surface-water for needed time with a small opening of the pond to minimize the evaporation in the deeper ponds; (photo-credit: Authors).

The coastal zone specific initiatives such as the Integrated Coastal Zone Management Programme $(17,18,31,32)$ and also the agriculture sector projects (e.g. LACC-II, DCRMA) for the coastal area have incorporated livelihoods-based approaches as well and initiated identifying coastal zone specific adaptation measures in recent years. Figure 5(a) and 5(b) are depicting some of the coastal zone specific adaptations that are not only considering the climatic contexts but also focusing on the livelihoods issues in a coherent manner.

However, in both the cases the livelihoods contexts are given primacy in devising the climate change adaptation measures with a pro-poor manner. Ahmed and Choudhury [24] classified adaptation measures further and wrote that among these identified adaptive options, some initiatives would remain as the climate change only measures, some options would remain climate change and development questions and some options would remain as the development only measures. The challenge would be to find out the right combination and integrating among these varied adaptation options that would be required for respective 'geo-physical settings' and 'livelihoodsystems'. Setting and selecting these livelihood options are about stretching the limits of the local adaptive responses as well as the innovation, experiences, technologies appropriate to the livelihoods, culture and environment of the respective areas.

The agriculture sector initiatives identified that although the climatic conditions have a 'covariant' impacts or effects over agriculturally based livelihoods in the areas 
but the impacts varies for livelihoods groups differently. These relative differences are often associated with the 'idiosyncratic' natures or characteristics of the livelihood groups themselves. In devising and considering adaptation options these adaptation options needs to keep open for respective livelihood groups. Fishers need water to be retained for culture fisheries whereas the farmers need water for irrigation. Adaptation options requires to be kept open for both kind of situations and with a more solution oriented mindset for future changed conditions. But, this is also about bringing newer ideas/ experiences/technologies and innovations appropriate to the livelihoods-culture and environment. This is all about increasing the adaptive capacity in all spheres of 'adaptation' as well as in 'development' domain coherently. Figure 6 shows that how the adaptive capacity can be coherently balanced involving various livelihoodsbased adaptation options uniquely to different systems.

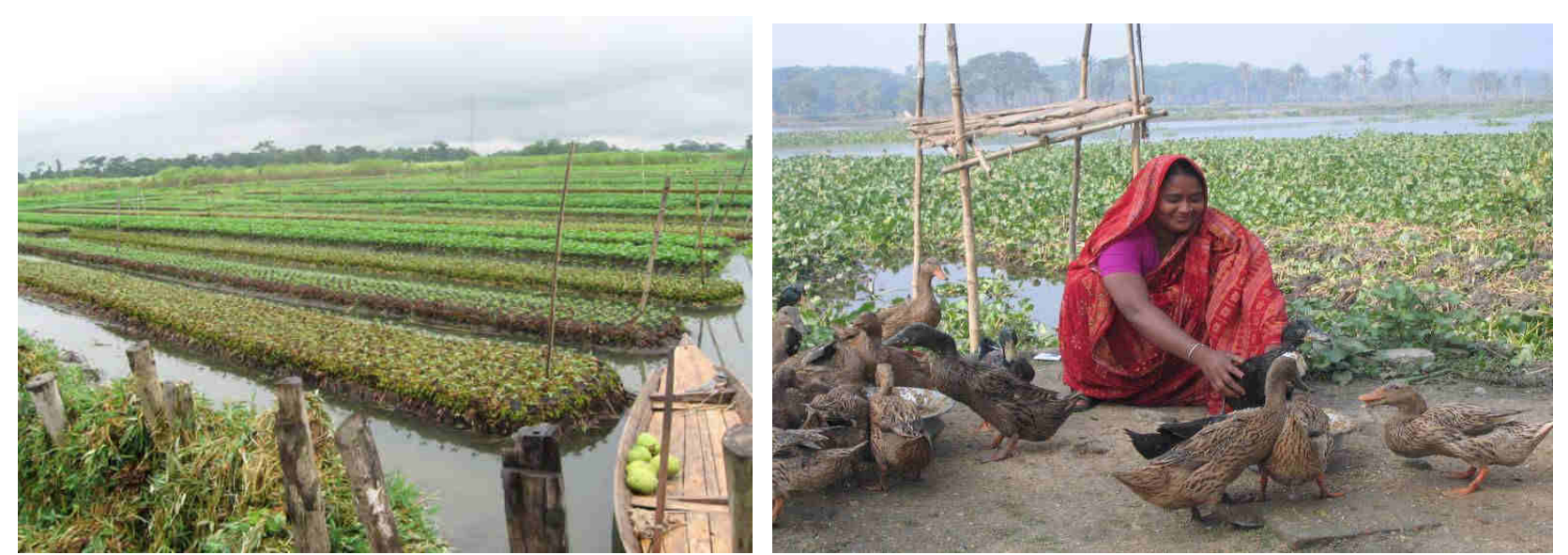

Fig.5: Coastal example: (5a-left) A typical floating garden (locally known as baira) that the coastal people are using for floating agriculture and adapting in the low-lying waterlogged coastal areas; (5b-right) a rural women has shifted her livelihoods from chicken rearing to duck rearing as the ducks can swim in the water and is not a risky livelihoods item.

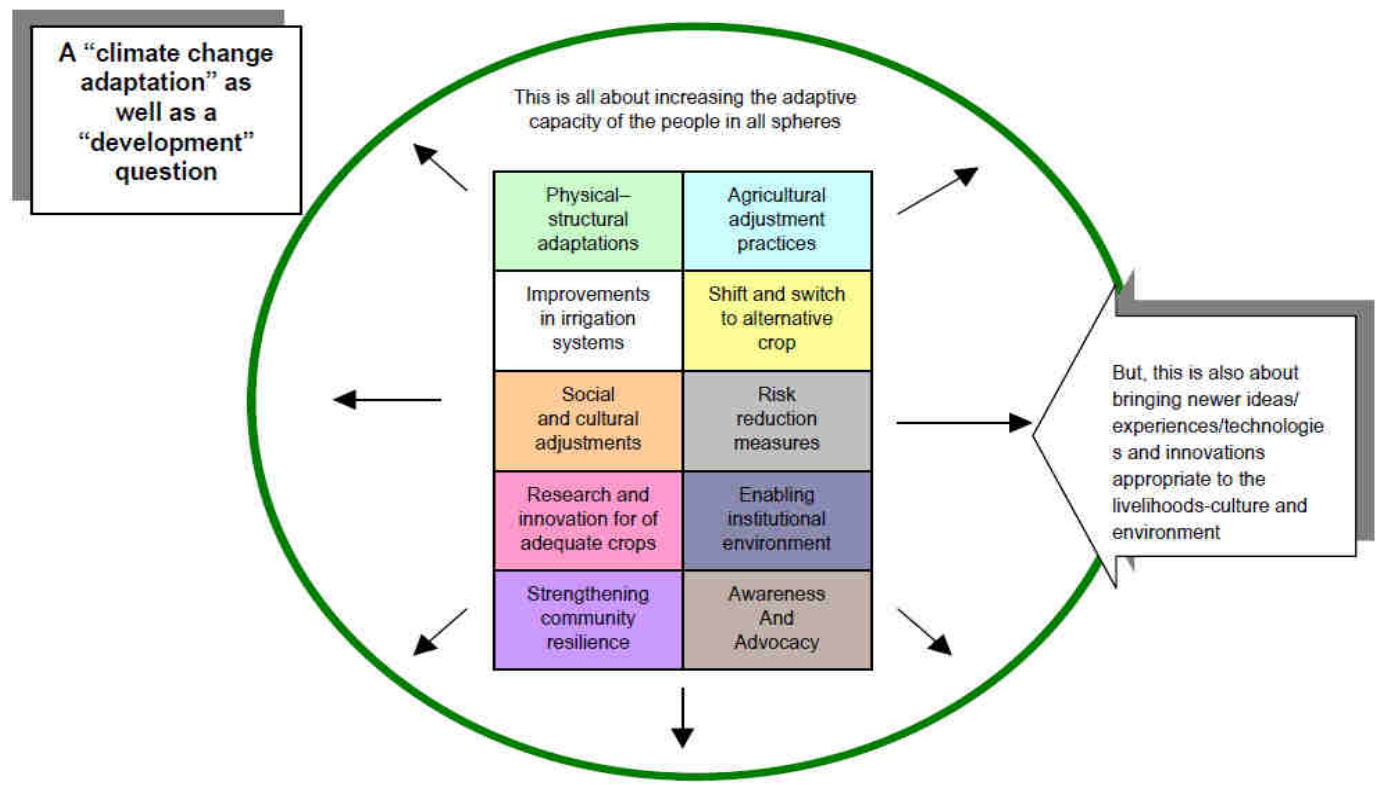

Fig.6: Key elements of framing livelihoods adaptation initiatives in agriculture sector (Source: Ahmed \& Chowdhury 2006).

\section{DISCUSSIONS}

Based on the experiences and lessons learned from these initiatives, some essential characteristics emerged. It was found that a successful climate change adaptation cannot be just done through top down national adaptation programs rather in Bangladesh should be incorporative of multiple characteristics of nature, society, culture, economy-livelihoods and various measures nested in climatic and societal systems coherently. These characteristics could be inclusive of livelihoods-based approaches which are inherently useful for pro-poor rural development and also for risk management and adaptations which are largely impacted by climate induced natural disasters and stresses in a country like 
Bangladesh. However, the experiences thereby brings along following few lessons which are elaborated in this discussion section below could be useful for future strategic and operational designing of climate, disaster and development initiatives in various parts of the country but also could bring good lessons for similar contexts in other places of globally.

Understanding the climate risks. Understanding of the livelihoods systems and its current and future risks are essential elements. In many cases the advanced risk assessment information, downscaled future climate scenarios is needed for decision making for adaptation but this type of future climate information may not be available on the ground. However, it should not stop stakeholders to move ahead with taking climate actions for their localities or sectors. In these cases, communities and sectors may just consider past disaster/stress related worst case information. A simple memory or worst case scenario may fill the gap and can be taken as a scenario to adapt for future occasions. These could be the starting points for climate actions on the ground and gradually with better information and consensus, adaptation measures and options cane designed and communities could be able to adapt to those situations and when needed consider even higher degree of thresholds to cover unknown levels [24, 26, 42,43].

Strategic integration. A successful adaptation program should not be built on isolation rather should have provisions for integration with the existing initiatives of poverty, livelihoods, DRR \& CCA interventions, policies, plans etc. [34,35]. This allows to stock-take, build on existing efforts and adapt jointly with support and knowledge together that is critical for livelihoods adaptation at all levels. This is also essential that livelihoods groups and their regular disaster, climate and development plans are harmonized at a local level and with local institutional setups [36].

Diversification of livelihood options. An essential characteristics of a livelihoods sustainability under changing climatic conditions is how far the livelihoods system can diversify itself and absorb shock and alter shock. In this respect diversification could be on agricultural practices, livelihoods strategies, alterative income sources, diversification of markets and even in some cases diversify and male connectivity with various different stakeholders that the regular business as usual $[13,24,25]$.

Climate forecast information (early warning, climate services). With the growing manifestation of climate induced natural hazards its now quite necessary that the livelihoods groups have access to some of the weather and climate related information that are essentially come out of the National Meteorological and Hydrological Services (in Bangladesh, the information is disseminated from Bangladesh Meteorological Department, Flood Forecasting Warning Center, Department of Disaster Management and respective ministries). For future resilience, a forecast based livelihoods practices in a service mode is more mandated from the national level which could be easily be accessed by the communities to prepare themselves to the risks and seasonal preparedness in a more effective way [37-39]. The climate forecasts are also changing these days and getting into a more service based approaches which would be more useful for the livelihoods groups on the ground [40].

Knowledge, technology \& innovation. Communities in their own domains often exchange technologies but in the face of changing climate a new type of knowledge and innovation often is demanded. Livelihoods-adaptation hence requires a regular process of exchange of new knowledge and for innovative adaptation. Livelihoods practices might also require new skills for to deal with newer type of arrangements. In the drylands it was found that the technological innovation is needed for finding drought tolerant varieties of rice or finding alternative livelihood measures that are less vulnerable to the climatic extremes and more resilient to the changing and variable climate $[34,24,25,43]$.

Gender and inclusive participation. The issues of gender and inclusive participation are critically important to deal with changing climate. Mainstreaming gender sensitive approaches in the adaptation programming is not only a great need but an issues of right as women are often remain as the first responders to the crisis that derive from climate induced natural disasters at local level. Women are the protectors of livelihoods on one hand and also the person who takes care and safeguard the family during the disasters and critical conditions in a culturally and environmentally constructed niche $[10,41,43]$.

Ready to try-out various options. In order to adjust with the new technologies and newer methods to deal with changing and variable climate stakeholders should be open to various types of piloting exercises. Piloting and testing are often cost intensive for the poorer and vulnerable people. In this respect, the catalyzing stakeholders, business communities, government service providers should play a leading role to engage for some seasons to bring about experience based tryouts conducive to the livelihoods settings. Trials and pilot 
should be regularly taken under systematic monitoring, learning \& uptake measure so that in future the successful adaptation options can be up-scaled and wide-scaled in a systematic manner [25,24,43]. In this respect, the adaptive capacity building through education, awareness, and skills-development are essential for livelihoods-based adaptation [26].

Local institutional re-alignment and resource mobilization. Planning to deal with changing climate and bringing adaptation in successful manner would demand better provisions, systems and institutional alignments. In this respect, re-alignment of institutional setups might be needed to adapt to the changing roles and settings. LACC initiative has shown some good example of how the technical working groups and farmer's/climate field schools can be better usefully re-aligned and used to address the issues that are required for new planning and programming. This type of institutional re-alignment could also be effectively utilized for knowledge and skill development and various types of resource mobilization that are often required for livelihoods adaptation at local level but soliciting support from various scales [7,24,32] The diagram (Figure 7) points out the above issue in a coherent manner.

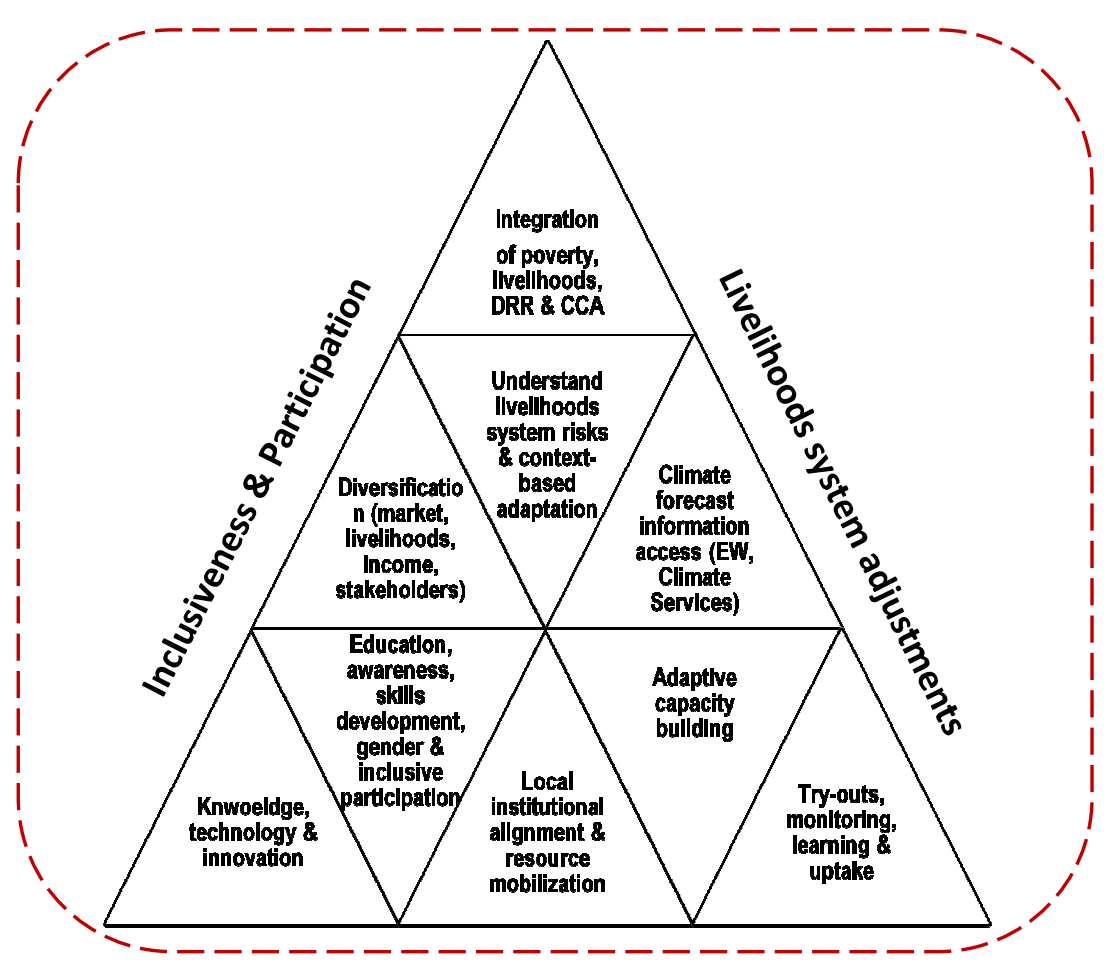

Fig.7: A diagrammatic view of few essential elements for livelihoods-based climate change adaptation that are often identified from various initiatives (Source: Author's analysis).

\section{CONCLUSIONS}

The agriculture sector initiatives in Bangladesh have brought up many interesting conclusions that are discussed in this paper. It was found that initiatives taken whether these are from climate change adaptation, disaster risk reduction or just simply sectoral development, adoption of livelihoods approach gives the interventions more smooth entry to the local issues, problems, local adaptation measures. This also allows the projects and initiative on the hand more 'local acceptability' where the stakeholders at local level through their participation can grow towards an 'adaptive learning' pathway to immediate and future adaptation to changing climate.
One of the practical conclusions emerged is that at local level climate change adaptation and development issues are not necessarily separated by the communities. On contrary issues at local level are seen as closely interlinked with people's 'livelihood activities' and 'livelihoods systems'. Resolving issues for development or climate change adaptation, thereby, does always require separate isolated interventions rather requires systematic integration of livelihoods approach. People in the communities are often more concerned about their immediate livelihood activities rather than other factors of adaptation for long future. This means adaptation cannot be done in isolation it requires seamless integration with the people's days to activities which is eventually linked 
to their livelihood systems. Adaptation means not only protecting their livelihoods but also improving and diversifying livelihoods through participation and engagement at all levels.

The findings indicated that climate change adaptation measures can be usefully designed and effectively developed if the issues of livelihoods protection, livelihoods security, early warning and resiliency are considered from the beginning of any initiative. In order to promote livelihoods-based adaptation host of issues including the institutional capacity building at multiple scales targeting local applications are essential way forward. In changing climatic conditions who does what and how-best are preconditions of better planning and stakeholder engagement strategy is an essential process that requires custom-based approaches for each of the livelihood-groups or livelihood-systems often separately. The strategy for small farmers may not necessarily would serve the purpose for small scale fishermen in the same locality. The lessons also suggested that the planning process and procedures should be inclusive of livelihoods systems and the profiles for each livelihood-group needs to be considered systematically.

Indigenous and local knowledge derived from livelihood practices could be critical factors for adaptation as well. This 'societal learning and knowledge' of adaptation should also be integrated to the external 'know-hows' that could help manage future risks in a gradual manner. For livelihoods adaptation some level of 'trial and error' with the adaptive practices and livelihoods options might also be needed where livelihoods-based approaches can play a key role in adapting to the future conditions. Adapting to the future conditions, hence, should build on 'adaptive learning pathways' that people can learn and iterate their course of developments as and when needed.

At policy level, these findings and lessons are valuable and guiding the future implementation of national and local actions for all three post-2015 frameworks (SFDRR [21], SDGs [19], and Paris Agreement [20]). All three global guidance are asking for harmonized climate actions that can be taken to the ground level. These lessons suggest that the livelihoods-based adaptation process enables significant modalities for a natural integration of issues disaster, climate and development in a coherent manner for local levels. Taking the livelihoods-based approaches more seriously and more context-based manner would enable the future national initiatives more conducive to these frameworks on one side and also make the local livelihoods and local communities resilient for future with locally conducive actions.

\section{ACKNOWLEDGEMENTS}

The authors acknowledge contributions of all those who remained involved with SSDP, LACC and DCRMA projects from the Department of Agricultural Extension (DAE) Bangladesh, Food and Agriculture Organization (FAO), Asian Disaster Preparedness Center (ADPC), Center for Environment and Geographic Information Services (CEGIS), Comprehensive Disaster Risk Management (CDMP) program and others.

\section{REFERENCES}

[1] Carney, D. (ed.) (1998) Sustainable Rural Livelihoods: What contribution can we make? London: Department for International Development.

[2] Chambers, R. and Conway, G.R. (1992) 'Sustainable Rural Livelihoods: Practical Concepts for the 21st Century', Discussion Paper 296. Brighton, UK: Institute of Development Studies.

[3] Chambers, R. (1995) 'Poverty and Livelihoods: Whose Reality Counts?' Discussion Paper 347. Brighton, UK: Institute of Development Studies.

[4] Tanner, T., Lewis, D., Wrathall, D., Bronen, R., Cradock-Henry, N., Huq, S., Lawless, C., Nawrotzki, R., Prasad, V., Rahman, Md. A., Alaniz, R., King, K., McNamara, K., Nadiruzzaman, Md., HenlyShepard, S. and Thomalla, F. (2015) Livelihood resilience in the face of climate change, Nature Climate Change 5: 23-26. DOI: 10.1038/NCLIMATE2431.

[5] World Bank. (2001). World Development Report 2000/2001: Attacking Poverty. World Development Report; New York: Oxford University Press.

[6] Gaillard, J.C. (2010) Vulnerability, capacity and resilience: perspectives for climate and development policy. J Int Dev 22:218-232.

[7] Adger, N.; Arnell, N.; Tompkins, E. (2005). Successful adaptation to climate change across scales. Global Environmental Change 15, 77-86.

[8] Ahmed, A.K. (2006). Concepts and Practices of "Resilience": a compilation from various secondary sources, US IOTWS; USAID, Bangkok, 2006. doi:10.13140/RG.2.1.2477.9927.

[9] Mitchell, T.; Ibrahim, M.; Harris, K.; Ahmed, A.K.; Hedger, M.; Polack, E.; Hall, N.; Hawrylyshyn, K.; Nightingale, K.; Onyango, M.; Adow, M., and Sajjad Mohammed, S. (2010). Climate Smart Disaster Risk Management. Strengthening Climate Resilience, Brighton: IDS.

[10] Wisner, Ben. (2010), Climate change and cultural diversity. International Social Science Journal, 61: 131-140. doi:10.1111/j.1468-2451.2010.01752.x. 
[11]Carney, D. (2002) Sustainable Livelihoods Approaches: Progress and Possibilities for Change. London: Department for International Development.

[12] Farrington, J., Carney, D., Ashley, C. and Turton, C. (1999). Sustainable livelihoods in practice: early application of concepts in rural areas. In Natural Resources Perspectives 42. London: Overseas Development Institute.

[13] Scoones, Ian (2009). Livelihoods perspectives and rural development. In The Journal of Peasant Studies. Vol. 36, Issue 1.

[14] Toufique, K.A.; Turton, C. (2003). Hands not land: how livelihoods are changing in rural Bangladesh. Bangladesh Institute of Development Studies: Dhaka.

[15]Ellis, F. (2000). Mixing It: Rural Livelihoods and Diversity in Developing Countries. Oxford: Oxford University Press.

[16]IPCC. (2014). Climate Change 2014: Impacts, Adaptation, and Vulnerability. Part A: Global and Sectoral Aspects. Contribution of Working Group II to the Fifth Assessment Report of the Intergovernmental Panel on Climate Change. Cambridge University Press, Cambridge, United Kingdom and New York, NY, USA.

[17] Ahmed, A.K., and Yasmeen, A. (2016). Vulnerability analysis of the coastal livelihoods in Bangladesh: does vulnerability construct through exogenous drivers or due to endogenous realities? Int. J. of Adv. Res. 4 (9). 827-839] (ISSN 2320-5407). http://dx.doi.org/10.21474/IJAR01/1551

[18]CEGIS. (2004). Vulnerability Analysis of Major Livelihood Groups in the Coastal Zone of Bangladesh. Dhaka, Bangladesh.

[19] United Nations. (2015). Transforming our World: The 2030 Agenda for Sustainable Development.

[20] UNFCCC. (2015). Adoption of the Paris Agreement. [FCCC/CP/2015/L.9/Rev.1]. United Nations Framework Convention for Climate Change and United Nations. December, 2015. Paris.

[21]UNISDR. (2015). Sendai Framework for Disaster Risk Reduction (SFDRR).

[22] CLP. (2002). Programme Memorandum. Bangladesh Char Livelihoods Programme, DFID and GOB. September 2002: Dhaka.

[23]CARE-Bangladesh. (2005). Rural Livelihood Programme: Capturing Lessons Learned - Final Report. CARE-Bangladesh/DFID, Rural Livelihood Programme (RLP). Dhaka.

[24] Ahmed, A.K. and Chowdhury, E.H. (2006). Study on livelihood systems assessment, vulnerable groups profiling and livelihood adaptation to climate hazard and long term climate change in drought prone areas of NW Bangladesh, Final report. Food and
Agriculture Organization (FAO) of the United Nations and Department of Agricultural Extension, Dhaka, Bangladesh, pp 64-104. http://www.fao.org/sd/dim_pe4/pe4_060701_en.htm

[25] Selvaraju, R.; Subbiah. A.R.; Bass. S.; Juergens, I. (2006). Livelihood adaptation to climate variability and change in drought-prone areas of Bangladesh: developing institutions and options: case study. Food and Agriculture Organization (FAO), Institutions for Rural Development, No. 5 (February), Rome. Available at: ftp://ftp.fao.org/docrep/fao/009/a0820e/a0820e.pdf

[26] Ahmed, A.K. (2010). Adaptive Learning in Climate Risk Management: Reflections on Capacity Building of Livelihoods Adaptation to Climate Change (Phase-II) in Bangladesh, Bangkok, 2010. doi:10.13140/RG.2.1.1691.5609.

[27]Hassan, A.W. R.; Shaw, R. (2015). Livelihood Security: Implications from Agriculture Sectors. In Habiba, U., Abedin, M.A., Hassan, A.W.R.; Shaw, R. Food Security and Risk Reduction in Bangladesh.

[28] Habiba, U.; Abedin, M.A.; Hassan, A.W.R.; Shaw, R. (2015). Food Security and Risk Reduction in Bangladesh, 2015. doi:10.1007/978-4-431-55411-0.

[29]MOWR. (2005). National Coastal Zone Policy. Ministry of Water Resources, Government of Bangladesh.

[30]MOWR. (2006). Coastal Development Strategy: Bangladesh. Ministry of Water Resources, Government of Bangladesh.

[31] Islam, M. R. (ed.) (2004). Where land meets the sea: a profile of the coastal zone of Bangladesh. Dhaka.

[32]PDO-ICZM (2002). Perceptions of Direct Stakeholders on Coastal livelihoods - Working Paper. Program Development Office for Integrated Coastal Zone Management (PDO-ICZM), Water Resources Planning Organization, Dhaka.

[33] Ahmed, A.K. (2005). Strengthening Disaster Risk Management in the Agricultural Sector in Bangladesh, Dhaka, 2005. http://www.fao.org/sd/dim_pe4/pe4_051201_en.htm

[34] MoEF. (2008). Bangladesh Climate Change Strategy and Action Plan 2008. Ministry of Environment and Forests (MoEF), Government of the People's Republic of Bangladesh, Dhaka, Bangladesh.

[35] Government of Bangladesh. (2005). National adaptation program of action. Ministry of Environment and Forest (MOEF), extracted from UNFCC http://unfccc.int/resource/docs/napa/ban01.pdf

[36] Ahmed, A.K. (2003). Local Level Institutional Arrangements in Khulna-Jessore Drainage Area: a 
case study, Integrated Coastal Zone Management Programme (ICZMP), Bangladesh: Dhaka.

[37]WMO-GFCS. (2016). Climate Services for Supporting Climate Change Adaptation - Supplement to the Technical Guidelines for the National Adaptation Plan Process.

[38] Ahmed, A.K., Basnayake, S., and Ahmed, S. (2016). Preparing to Face Hotter, Drier and Wetter Future: Strengthening Weather and Climate Services through National and Regional Collaborations in Bangladesh, The Daily Independent. 23 March, 2016: Dhaka. http://www.eindependentbd.com/arc/pre_page/201603-23/17.

[39] Ahmed, A.K. (2013). Mainstreaming in Changing Climate and Extremes: Emerging Pathways to Integrate Risk Foresight and Climate Services into Development Processes, Asian Disaster Management. News. 19. Bangkok.

[40] Ahmed, A.K. (2015). Changing Landscape of Early Warning Systems: Reflections on the Asia-Pacific region's developments, challenges and future pathways from a practitioner's perspective, Asian Disaster Management News. 21, 2015, Pg 4-7. Bangkok.

[41] Yasmeen, A and Murshid, S. (2004). Women of the Coast: A Gender Status Paper on the Coastal Zone (WP 027), Program Development Office for Integrated Coastal Zone Management Plan Project; Bangladesh. Dhaka.

[42] Government of Bangladesh (2014). Inception Report: Bangladesh Delta Plan 20100 (BDP2100) Formulation Project. General Economics Division, Planning Commission, November, 2014: Dhaka.

[43] Ahmed, A.K. (2016). Facing Seasonal Crisis and 'monga' in the North-Western Bangladesh: Transforming Vulnerability into Resilience. Asian Journal of Social Sciences \& Humanities. Vol. 5(4) November 2016. http://www.ajssh.leenaluna.co.jp/AJSSHPDFs/Vol.5(4)/AJSSH2016(5.403).pdf 